Trauma Surgery \& Acute Care Open

\section{CT scan incidental findings in trauma patients: does it impact hospital length of stay?}

\author{
Peter Andrawes, ${ }^{1}$ Antonio I Picon, ${ }^{1,2}$ Masood A Shariff, ${ }^{1}$ Basem Azab, ${ }^{1}$ \\ Wolf von Waagner, ${ }^{1}$ Seleshi Demissie, ${ }^{3}$ Charles Fasanya ${ }^{1,4}$
}

'Department of Surgery, Staten Island University Hospital, Northwell Health System, Hofstra School of Medicine, New York, USA

${ }^{2}$ Department of SurgerySurgical Oncology, Staten Island University Hospital, Northwell Health System, Hofstra School of Medicine, New York, USA ${ }^{3}$ Biostatistics Unit, Feinstein Institute for Medical Research at Staten Island University Hospital, Northwell Health System, Hofstra School of Medicine, New York, USA

${ }^{4}$ Department of Trauma and Critical Care, Staten Island University Hospital, Northwell Health System, Hofstra School of Medicine, New York, USA

Correspondence to Dr Peter Andrawes; peterabotaga@yahoo.com, pabotaga@gmail.com

This paper was presented at the 2016 TQIP Annual Meeting in Orlando, Florida.

Received 22 March 2017 Revised 18 July 2017

Accepted 8 August 2017

\footnotetext{
To cite: Andrawes $P$, Picon Al, Shariff MA, et al. Trauma Surg Acute Care Open 2017;2:1-6.
}

\section{ABSTRACT}

Background CT scans are heavily relied on for assessment of solid organ injuries complementing clinical examination. These CT scans could also reveal pathologies not related to trauma called incidental findings. We aimed to evaluate the frequency of these findings and their outcome on hospital services. Methods A retrospective chart review of prospectively collected data of the emergency department's trauma database from January 2005 to December 2011 to evaluate incidental findings on CT scans on trauma admissions. These incidental findings were divided into three classes: class 1-minor degenerative, nondegenerative, normal variants or congenital finding that does not require further investigation or workup; class 2-findings not requiring urgent intervention with scheduled outpatient follow-up and class 3-all findings that require urgent evaluation/further investigation during the same hospital admission. One-year follow-up was done to review hospital length of stay, trauma clinic follow-up and post-trauma surgery.

Results of 1000 charts reviewed, 957 were selected after 43 patients were excluded due to incomplete documentation. Of the 957 patients, 385 (40\%) were found to have incidental findings. A total of 560 incidental findings were found on the CT scan reports with one-third of patients having multiple findings (144 patients, 37.4\%). The largest number of incidental findings were in class 2 . The incidental group had significantly longer length of stay after adjusted multivariate analysis ( $8.7 \pm 0.48$ vs $6.7 \pm 0.55, p=0.005)$. Conclusion The incidental findings are commonly found during CT imaging in trauma centers and our rate was 40\%. Appropriate documentation, communication and follow-up of those findings is necessary. A classification system for these findings practiced nationwide will aid in categorizing the urgency of continued follow-up. This also will help decrease the length of hospital stay and healthcare cost.

Level of evidence Level 4

\section{INTRODUCTION}

Except for cardiac events and cancer, trauma remains one of the leading causes of morbidity and mortality in the USA. Based on the US Census Bureau, in 2009 there were 10.8 million accidents leading to over 35900 deaths. ${ }^{1}$ Trauma is still the leading cause of death among teenagers and a major cause of morbidity and mortality among the elderly, which is a growing area of concern. ${ }^{2}$ The modern trauma centers rely heavily on CT scans for assessment of solid organ injuries. Besides providing information on acute trauma-related injuries, CT scans could also reveal pathologies not related to trauma called 'incidental findings', which may or may not require further investigation. ${ }^{3-6}$

The diagnosis and correct treatment of these incidental findings could have an impact on patient's future health. The frequency of incidental findings varies from institution to institution ${ }^{48}$ as it depends on patient population, volume of trauma, type of trauma and resources available at the trauma center. The number of incidental findings based on previous published articles has been variable from $30 \%$ to as high as $53 \% .^{9-14}$ The aim of this study is to determine the frequency of incidental findings in a level 1 trauma center, hospital length of stay, any intervention performed during or after the admission and 1-year follow-up. The incidental findings will allow for development of a classification system that can be applied to these findings, which will help in their management, improve patient awareness and follow-up.

\section{METHODS}

Study design

We performed a retrospective chart review of all patients who were admitted with a trauma diagnosis from a prospectively maintained New York State Trauma Registry emergency department database between January 2005 and December 2011. Data were collected from electronic medical records with inclusion criteria being all patients who received a CT scan of the head, cervical spine, chest, abdomen and pelvis and/or total body scan that were admitted to the trauma service. Any patient who did not have a CT scan was excluded. The CT scans were reviewed for any type of incidental finding noted on the definitive radiology report. The course of in-hospital stay was reviewed for demographics, past medical history (smoking history, cardiopulmonary disease, history of cancer, any surgical intervention), trauma type (blunt, penetrating), trauma classification (fall, motor vehicle accident (MVA), pedestrian, assault, gunshot wound, stab, other), number of body part involved, injury severity score (ISS), length of stay and discharge disposition. Fall category comprised of all patients with the admitting diagnostic category as fall in the New York Trauma registry. In trauma classification, the 'other' category was defined as home accidents, foreign body injuries or blast injury.

The primary outcomes were to determine the frequency of incidental findings in our patient population and hospital length of stay. The secondary 
outcomes were chart review of 1-year follow-up of patients with inpatient and outpatient clinics with any incidental finding intervention (ie, pathology report, radiology scans, surgical intervention), 1-year mortality and intensive care unit (ICU) admission.

One thousand charts were reviewed based on the inclusion/ exclusion criteria. Data were collected on the number of incidental findings reported by board certified radiologists on CT scans. An incidental finding was defined as an abnormal finding not related to trauma seen in CT scan imaging. ${ }^{12}$ The incidental findings were further classified into three classes based on classification used in the literature ${ }^{79^{12-15}}$ :

Class 1: includes minor degenerative, non-degenerative, normal variants or a congenital finding that does not require further investigation or workup.

Class 2: includes finding that did not require urgent intervention. However, an outpatient follow-up within 3 months to 1 year is necessary.

Class 3: includes all findings that require urgent evaluation or further investigation before hospital discharge or soon after discharge.

For each incidental finding, we reviewed currently available guidelines and articles to determine the recommended management and clinical importance of the incidental findings. ${ }^{12} 16-19$

\section{Statistical analysis}

Summary statistics for demographic and baseline clinical characteristics are presented for all patients. Categorical data are summarized using frequency counts and percentages. Descriptive statistics summarize continuous variables, including mean and SD.

Comparisons were made between the incidental and non-incidental groups. To identify potential confounding factors, initial univariate analyses were conducted for all the demographic and clinical variables comparing incidental and non-incidental groups. For categorical variables, comparisons were made using a $\chi^{2}$ test or Fisher's exact test as appropriate. For continuous variables, comparisons were made using an independent groups t-test, or a Wilcoxon-Mann-Whitney U test for skewed variables.

Multivariate models for each of the outcomes (length of stay, 1-year mortality and ICU admission) were developed to adjust for the potential confounding effect of demographic and clinical risk factors. Among the many potential confounding factors, age $>65$ years, prior surgery, history of cardiopulmonary and ISS were selected to be included in the multivariate analyses based on unadjusted $\mathrm{p}$ values of the univariate tests $(\mathrm{p}<0.05)$ and on clinical considerations.

All statistical tests were two-sided, and there was no adjustment for multiple testing. A p value of $<0.05$ was considered to indicate statistical significance. All the data analyses were performed using SAS (Statistical Analysis System) software V.9.3.

\section{RESULT}

One thousand charts were reviewed and 957 were selected. Forty-three charts were excluded due to incomplete documentation. Out of those 957,385 patients $(40 \%)$ were found to have incidental findings. A total of 560 incidental findings were found on CT scan reports and, of these, more than one-third of the patients had multiple incidental findings (144 patients, 37\%). Table 1 lists the baseline patient characteristics and inpatient outcomes for overall group and subgroups of incidental and non-incidental findings. The mean age of all patients was $54.3 \pm 27.6$ years; the age for patients with incidental findings was much higher compared with patients without, $62.0 \pm 22.3$
Table 1 Baseline characteristics and trauma-related outcomes

\begin{tabular}{|c|c|c|c|c|}
\hline & Overall & $\begin{array}{l}\text { Positive } \\
\text { findings }\end{array}$ & $\begin{array}{l}\text { Negative } \\
\text { findings }\end{array}$ & $\mathrm{p}$ Value \\
\hline & $\mathrm{n}=957$ & $n=385$ & $n=572$ & \\
\hline \multicolumn{5}{|l|}{ Characteristics } \\
\hline Age (years) & $54.3 \pm 27.6$ & $62.0 \pm 22.3$ & $49.2 \pm 29.5$ & 0.0001 \\
\hline Median (range) & $58(<1-100)$ & $66.3(<1-98)$ & $47(<1-98)$ & \\
\hline Elderly, $\geq 65$ years & $424(44.3)$ & $204(53.0)$ & $220(38.5)$ & \\
\hline Gender & & & & 0.2828 \\
\hline Male & $572(59.8)$ & $222(57.7)$ & $350(61.2)$ & \\
\hline Female & $385(40.2)$ & $163(42.3)$ & $222(38.8)$ & \\
\hline Caucasian, race & $816(85.3)$ & $335(87.0)$ & 481 (84.1) & 0.2273 \\
\hline $\begin{array}{l}\text { Body mass index, } \\
\mathrm{kg} / \mathrm{m}^{2}\end{array}$ & $25.9 \pm 6.6$ & $26.6 \pm 9.4$ & $26.2 \pm 8.8$ & 0.5948 \\
\hline Current smoker & 331 (34.6) & $136(35.3)$ & 195 (34.1) & 0.7291 \\
\hline $\begin{array}{l}\text { Cardiopulmonary } \\
\text { disease }\end{array}$ & $490(51.2)$ & $224(58.2)$ & $266(46.5)$ & 0.0005 \\
\hline Diabetes & $55(5.7)$ & $24(6.2)$ & $31(5.4)$ & 0.6713 \\
\hline Hypertension & $147(15.4)$ & $60(15.6)$ & $87(15.2)$ & 0.9272 \\
\hline $\begin{array}{l}\text { Coronary artery } \\
\text { disease }\end{array}$ & $34(3.6)$ & $19(4.9)$ & $15(2.6)$ & 0.0740 \\
\hline Pulmonary disease & $20(2.1)$ & $10(2.6)$ & $10(1.7)$ & 0.3681 \\
\hline Alcoholism & $14(1.5)$ & $8(2.1)$ & $6(1)$ & 0.2717 \\
\hline History of cancer & $85(8.9)$ & $32(8.3)$ & $53(9.3)$ & 0.6445 \\
\hline $\begin{array}{l}\text { History of prior } \\
\text { surgery }\end{array}$ & $443(46.3)$ & $200(51.9)$ & $243(42.5)$ & 0.0045 \\
\hline \multicolumn{5}{|l|}{ Trauma classification } \\
\hline Fall & $551(57.6)$ & $238(61.8)$ & $313(54.7)$ & 0.0328 \\
\hline $\begin{array}{l}\text { Motor vehicle } \\
\text { accident }\end{array}$ & $217(22.7)$ & $99(25.7)$ & $118(20.6)$ & 0.0704 \\
\hline Pedestrian & $55(5.7)$ & $22(5.7)$ & $33(5.8)$ & NS \\
\hline Assault & $56(5.9)$ & $16(4.2)$ & $40(7.0)$ & 0.0693 \\
\hline Gunshot wound & $8(0.8)$ & $1(0.3)$ & $7(1.2)$ & 0.1535 \\
\hline Stab & $11(1.1)$ & 0 & $11(1.9)$ & 0.0041 \\
\hline Other & $59(6.2)$ & $9(2.3)$ & $50(8.7)$ & NS \\
\hline Trauma type & & & & 0.0124 \\
\hline Blunt & $919(96.0)$ & $378(98.2)$ & 541 (94.6) & \\
\hline Penetrating & $24(2.5)$ & $3(0.8)$ & $21(3.7)$ & \\
\hline Other & $14(1.5)$ & $4(1)$ & $10(1.7)$ & \\
\hline Injury severity score & $13.5 \pm 7.7$ & $14.2 \pm 7.8$ & $13.1 \pm 7.7$ & 0.0325 \\
\hline Median (range) & $10(1-66)$ & $13(1-50)$ & $10(1-66)$ & \\
\hline \multicolumn{5}{|l|}{ No. of CT scans } \\
\hline Head & $813(85.0)$ & $355(92.2)$ & $458(80.1)$ & 0.0001 \\
\hline Chest & $390(40.8)$ & $240(62.3)$ & $150(26.2)$ & 0.0001 \\
\hline $\begin{array}{l}\text { Abdomen and } \\
\text { pelvis }\end{array}$ & $617(64.5)$ & $356(92.5)$ & $261(45.6)$ & 0.0001 \\
\hline All of the above & $336(35.1)$ & $212(55.1)$ & $124(21.7)$ & 0.0001 \\
\hline $\begin{array}{l}\text { ICU admission } \\
\text { required }\end{array}$ & $268(28.0)$ & $133(34.5)$ & $135(23.6)$ & 0.0002 \\
\hline $\begin{array}{l}\text { Hospital length of } \\
\text { stay }\end{array}$ & $7.3 \pm 10.1$ & $8.7 \pm 12.8$ & $6.4 \pm 7.7$ & 0.0012 \\
\hline Median (range) & $5(1-175)$ & $6(1-175)$ & $4(1-96)$ & \\
\hline $\begin{array}{l}\text { Discharge } \\
\text { disposition }\end{array}$ & & & & $<0.0001$ \\
\hline Home & $540(56.4)$ & $187(48.6)$ & $353(61.7)$ & \\
\hline Rehab unit & $191(20.0)$ & $94(24.4)$ & $97(17.0)$ & \\
\hline
\end{tabular}


Table 1 Continued

\begin{tabular}{lllll}
\hline & Overall & $\begin{array}{l}\text { Positive } \\
\text { findings }\end{array}$ & $\begin{array}{l}\text { Negative } \\
\text { findings }\end{array} \quad$ p Value \\
\hline $\begin{array}{l}\text { Death } \\
\begin{array}{l}\text { Skilled nursing } \\
\text { facility }\end{array}\end{array}$ & $59(6.0)$ & $37(9.6)$ & $30(5.2)$ & \\
$\begin{array}{l}\text { Against medical } \\
\text { advice }\end{array}$ & $15(1.6)$ & $7(1.8)$ & $8(1.4)$ \\
\hline $\begin{array}{l}\text { Psychiatric unit } \\
\text { Other }\end{array}$ & $3(0.3)$ & $3(0.8)$ & 0 \\
\hline
\end{tabular}

Values are given as mean \pm SD with median and range for continuous, or $n(\%)$ for categorical.

ICU, intensive care unit; NS, no significance.

years vs $49.2 \pm 29.5$ years $(\mathrm{p}=0.0001)$, respectively. Patients aged $>65$ years totaled $44 \%$ of the study population and were found to have a significant number of incidental findings $(53 \%$ vs $39 \%, \mathrm{p}=0.0001)$. Of patient risk factors, cardiopulmonary disease was found in 51\% of the overall study group, with a significantly higher number of incidental findings found in patients with cardiopulmonary disease than those without $(58 \%$ vs $47 \%, p=0.0005)$. History of prior surgery was also significantly higher in patients with incidental findings when compared with those without ( $52 \%$ vs $43 \%, \mathrm{p}=0.0045)$.

In trauma classifications, falls were most common $(58 \%)$ followed by MVA (23\%), assault (6\%), pedestrian accident (6\%) and others. Falls were proportionally greater in the incidental group (62\% vs 55\%). The overall mean ISS was 13.5 \pm 7.7 . Between the groups, the mean ISS was higher in the incidental group by one point compared with the non-incidental group with significance $(14.2 \pm 7.8$ vs $.13 .1 \pm 7.7, \mathrm{p}=0.0325)$.

The number of CT scans patients received were quantified and separated between the two groups. A total of 1820 CT scans of the head, chest and abdomen/pelvis were performed and reviewed. The number of scans between groups is shown in table 1. A high number of scans for the head, chest and abdomen/pelvis had incidental findings (92\%, 62\% and 96\%, respectively) compared with non-incidental group (80\%, 26\% and 46\%, respectively); each group comparison was highly significant $(p<0.0001)$. A total of 337 findings (67\% of all incidental findings) were identified on CT scans of the abdomen and pelvis, the most of all CT scans performed. The least number of incidental findings were identified on CT scans of the head (28 findings, 5\%).

ICU admission was required for $28 \%$ of patients: incidental group 133 (35\%) and non-incidental group 135 (24\%) $(\mathrm{p}=0.0002)$. Overall hospital length of stay was $7.3 \pm 10.1$ days, with $8.7 \pm 12.8$ days taken by the incidental group to be discharged and $6.4 \pm 7.7$ days by the non-incidental group $(\mathrm{p}=0.0012)$.

Table 2 lists all incidental findings reported in the CT scan reports. The findings are categorized by classes defined above: class 1-51 (9\%); class 2-354 (63\%) and class 3-155 (28\%). The highest number of findings were in class 2 classification (did not require urgent intervention) followed by class 3 (findings requiring urgent evaluation) and class 1 (normal variants). Class 1 lesions were 51 (9\%) of our incidental findings. Class 2 included all adrenal and thyroid nodules, pleural and lung nodules and all types of cysts affecting kidneys and liver which do not require immediate or urgent intervention, but do require an appropriate follow-up. A total of 354 findings were defined as class $2(63 \%)$ and 155 findings were defined as class $3(28 \%)$. The most common incidental findings were found in kidneys
Table 2 Incidental finding by classification

\begin{tabular}{|c|c|}
\hline Total incidental findings & 560 \\
\hline Class 1 & $51(9.1)$ \\
\hline Sinus-polyp/cyst & $17(3)$ \\
\hline Bladder diverticulum & $7(1.3)$ \\
\hline Duodenal diverticulum & $5(0.9)$ \\
\hline Duplicate renal system & $4(0.7)$ \\
\hline \multicolumn{2}{|l|}{ Vertebral body } \\
\hline Hemangioma & $4(0.7)$ \\
\hline Accessory spleen & $3(0.5)$ \\
\hline Horse shoe kidney & $3(0.5)$ \\
\hline Bovine aortic arch & $3(0.5)$ \\
\hline Left-sided superior vena cava & $2(0.4)$ \\
\hline Adrenal mylolipoma & $2(0.4)$ \\
\hline Undescended testicle & $1(0.2)$ \\
\hline Class 2 & $354(63.2)$ \\
\hline Renal & $104(18.6)$ \\
\hline Kidney cyst & 91 \\
\hline Stone & 13 \\
\hline Lung nodule & $70(13)$ \\
\hline Thyroid nodule & $39(7)$ \\
\hline Adrenal nodule & $36(6.4)$ \\
\hline Ovarian cyst & $20(3.6)$ \\
\hline Hepatic cyst & $19(3.4)$ \\
\hline Spleen & $14(2.5)$ \\
\hline Hemangiomas & 13 \\
\hline Cyst & 1 \\
\hline Hiatal hernia & $10(1.8)$ \\
\hline Hernia & $8(1.4)$ \\
\hline Inguinal & 6 \\
\hline Umbilical & 2 \\
\hline Dilated intrahepatic ducts & $5(0.9)$ \\
\hline Uterine fibroid & $5(0.9)$ \\
\hline Prostate enlargement & $4(0.7)$ \\
\hline Gall stones & $4(0.7)$ \\
\hline Skin lesions (lipoma) & $4(0.7)$ \\
\hline Arachnoid cyst & $3(0.5)$ \\
\hline Hydrocele & $3(0.5)$ \\
\hline Diaphragmatic hernia & $2(0.4)$ \\
\hline Pleural nodule & $2(0.4)$ \\
\hline Splenomegaly & $1(0.2)$ \\
\hline Small bowel lesion (lipoma) & $1(0.2)$ \\
\hline Class 3 & $155(27.7)$ \\
\hline Kidney hypodense lesions & $36(6.4)$ \\
\hline Liver hypodense lesions & $30(5.4)$ \\
\hline Pancreatic mass type & $30(5.4)$ \\
\hline Hypodense lesions & 15 \\
\hline Cyst & 5 \\
\hline Mediastinal lymph node & $14(2.5)$ \\
\hline Brain lesion & $11(2)$ \\
\hline \multicolumn{2}{|l|}{ Abdominal aortic } \\
\hline Aneurysm & $11(2)$ \\
\hline Lung mass & $6(1.1)$ \\
\hline Breast & $5(0.9)$ \\
\hline
\end{tabular}

Continued 


\begin{tabular}{lc}
\hline Table 2 Continued & \\
\hline Total incidental findings & 560 \\
\hline lliac artery aneurysm & $3(0.5)$ \\
\hline Endometrial & $3(0.5)$ \\
\hline Thickening & 1 \\
\hline Mass & 2 \\
\hline Mediastinal & $3(0.5)$ \\
\hline Cyst & 1 \\
\hline Mass & 2 \\
\hline Colon lesion & $2(0.4)$ \\
\hline Suspicious lymph node & $2(0.4)$ \\
\hline Pelvic mass & $2(0.4)$ \\
\hline Stomach mass & $1(0.2)$ \\
\hline Subclavian artery aneurysm & $1(0.2)$ \\
\hline Renal artery aneurysm & $1(0.2)$ \\
\hline Vertebral artery aneurysm & $1(0.2)$ \\
\hline Mesenteric mass & $1(0.2)$ \\
\hline Bladder mass & $1(0.2)$ \\
\hline Basal ganglia mass & $1(0.2)$ \\
\hline
\end{tabular}

Data are presented as $\mathrm{N}(\%)$ of the total and $\mathrm{n}(\%)$ of the class findings.

(25\% of all incidental findings and $42 \%$ of the abdomen and pelvic CT scan findings). The second most common organ with incidental findings was lung with 76 incidental findings (14\%).

\begin{tabular}{|c|c|c|c|c|}
\hline & Class 1 & Class 2 & Class 3 & $\mathrm{p}$ Value \\
\hline $\mathrm{N}$ & 53 & 207 & 125 & \\
\hline Age (years) & $45.3 \pm 27.3$ & $62.3 \pm 20.7$ & $68.4 \pm 18.8$ & $<0.0001$ \\
\hline Elderly, $\geq 65$ years & $19(35.8)$ & $108(52.2)$ & 77 (61.6) & 0.0067 \\
\hline Injury severity score & $15.2 \pm 9.6$ & $15.4 \pm 8.7$ & $14.5 \pm 10.9$ & 0.2144 \\
\hline Trauma classification & & & & 0.3015 \\
\hline Fall & $24(45.3)$ & $126(60.9)$ & $88(70.4)$ & \\
\hline Motor vehicle accident & $20(37.7)$ & $55(26.6)$ & $24(19.2)$ & \\
\hline Pedestrian & $2(3.8)$ & $5(2.4)$ & $2(1.6)$ & \\
\hline Assault & $4(7.5)$ & $10(4.8)$ & $2(1.6)$ & \\
\hline Gunshot wound & 0 & $1(0.5)$ & 0 & \\
\hline Stab & $3(5.7)$ & $10(4.8)$ & $9(7.2)$ & \\
\hline Trauma type & & & & 0.165 \\
\hline Blunt & $50(94.3)$ & $204(98.6)$ & $124(99.2)$ & \\
\hline Penetrating & $1(1.9)$ & $2(1)$ & 0 & \\
\hline Other & $2(3.8)$ & $1(0.48)$ & $1(0.8)$ & \\
\hline Discharge disposition & & & & 0.9449 \\
\hline Home & $31(58.5)$ & $101(48.8)$ & $55(44)$ & \\
\hline Rehab unit & $13(24.5)$ & $47(22.7)$ & $34(27.2)$ & \\
\hline Death & $5(9.4)$ & $18(8.7)$ & $14(11.2)$ & \\
\hline Skilled nursing facility & $2(3.8)$ & $18(8.7)$ & $10(8)$ & \\
\hline Against medical advice & $0(0)$ & $4(1.9)$ & $3(2.4)$ & \\
\hline Psychiatric unit & $1(1.9)$ & $1(0.48)$ & $1(0.8)$ & \\
\hline Other & $1(1.9)$ & $18(8.7)$ & $8(6.4)$ & \\
\hline ICU admission required & $20(37.7)$ & $69(33.3)$ & $40(32)$ & 0.7574 \\
\hline Hospital length of stay & $7.2 \pm 6.9$ & $9.0 \pm 11$ & $9.8 \pm 17$ & 0.1206 \\
\hline
\end{tabular}

Categorical data are presented as number (\%) and continuous data as mean \pm SD. $\mathrm{ICU}$, intensive care unit
Table 4 Multivariate and OR analysis of length of stay, mortality and ICU admission

\begin{tabular}{lll}
\hline & Outcomes & p Value \\
\hline $\begin{array}{l}\text { Length of stay (least square mean) } \\
\text { Incidental findings }\end{array}$ & $8.7 \pm 0.48$ & 0.005 \\
$\quad$ Non-incidental findings & $6.7 \pm 0.55$ & \\
Mortality & & \\
OR (no vs yes) & $0.77(0.53,1.11)$ & 0.164 \\
ICU admission & & \\
$\quad$ OR (no vs yes) & $0.74(0.55,1.00)$ & 0.053 \\
\hline
\end{tabular}

The least square means and OR are adjusted for ISS, age, cardiopulmonary and prior surgery in a multivariate model for each of the outcomes. Least square means are presented with SEs. ORs are presented with $95 \% \mathrm{Cls}$.

ICU, intensive care unit; ISS, injury severity score.

Table 3 illustrates patient demographics for the incidental group according to different classifications. Patients with class 3 findings were found to have the longest hospital stays $(9.8 \pm 17$ days) followed by class 2 (9.0 $0 \pm 11.3$ days) and class 1 (7.2 \pm 6.9 days) without significance $(p=0.1206)$. Age and age $>65$ years, when compared by classification were still significant.

Follow-up outcomes of the trauma admission were reviewed and only $99(11 \%)$ patients had post-trauma follow-up visit in the trauma clinic (incidental group $36(10 \%)$ and non-incidental group $63(12 \%))$. Review of patients who had surgery in the same hospital admission for incidental finding revealed that one patient with abdominal aortic aneurysm underwent surgical repair. One-year follow-up with social security index was performed to review vital status of patients discharged alive at the time of the study resulted with an overall mortality of $19 \%$ (168 patients, excluding the in-hospital deaths). In the subgroups, the 1-year mortality was higher in the incidental group at $22 \%$ (76 patients) compared with the non-incidental group at $17 \%$ (92 patients), after excluding the in-hospital deaths.

Seven biopsies were done to evaluate masses for malignancy. Six were negative for malignancy and one patient was positive.

Table 4 presents the multivariate model of adjusted analysis for the significant findings of age $>65$ years, history of cardiopulmonary disease, history of prior surgery and ISS. It was found that the length of stay remained significant after adjusting for significant confounders $(8.7 \pm 0.48$ vs $6.7 \pm 0.55$, $\mathrm{p}=0.005$ ). One-year mortality and ICU admission were not significant when adjusted for incidental findings.

\section{DISCUSSION}

This study was conducted to evaluate the frequency, length of stay and follow-up on incidental findings in our trauma patient population and their disposition. These incidental findings were defined as pathologies not related to trauma, which may or may not require further investigation or intervention. ${ }^{89}$ These findings might be beneficial for earlier detection of diseases such as malignancy; however, it could also result in increased patient anxiety, length of stay and an impact on healthcare costs. ${ }^{8} 121320$

Our study showed that the percentage of the incidental findings in retrospective chart review was $40 \%$ in our trauma patients. Not surprisingly, most of the findings were discovered in CT scans of the abdomen and pelvis; CT scans of the head revealed the least number of findings, despite being the most frequently done. Sixty-three per cent of findings were defined as class 2 . These findings, when further investigated did not require immediate intervention or further diagnostic studies before discharge. 
However, given the frequency and relevance of the incidental findings, these findings should not be underestimated and some sort of follow-up is required. Therefore, the incidental findings should be communicated to the patient or their family members and documented in the chart. ${ }^{89}$ The association between the incidental findings and the gender in trauma population was reported to be different in various studies. Although Barboza et $a l^{19}$ did not find any association, Barrett et a ${ }^{14}$ and Pasluska et al reported the incidental findings to be more frequent in female patients. Our study demonstrated a higher frequency of incidental findings in female populations (42\%). Only one patient with an incidental finding on CT imaging required a surgery (abdominal aortic aneurysm repair) during the same admission. All other surgeries performed were trauma related.

What we also found is lack of documentation and lack of follow-up for these findings, which has a significant clinical and medico-legal ramification. ${ }^{9}{ }^{13}$ Poor documentation has been described previously, which we believe may be due to focusing more on the injuries from the trauma, which is expected, and not paying attention to these incidental findings. ${ }^{7912-14}$ Only $10 \%$ of our trauma patients had follow-up visits to our trauma clinic. To insure accurate documentation, a section was added in our history and physical, as well as our discharge instructions, which obligates the clinical staff to report whether or not incidental findings are found in our trauma imaging studies and the need for follow-up. ${ }^{13} 14$ Furthermore, a hard copy of the CT scan reports and imaging 'CD' should be provided to the patients to educate them about these findings and to prevent any further unnecessary or repeating imaging studies that might cause unnecessary increase in health cost.

A lot of studies have reported a scoring system or classification for these incidental findings per their clinical significance. ${ }^{3} 91012-14$ We have designed a classification to better evaluate these findings, which will help with further management. This classification will act as a guideline that will allow appropriate follow-up and resource distribution. A good referral system by emergency department physicians and trauma surgeons should be developed for adequate follow-up.

Class 3 findings, the most clinically concerning category, represents 28\% in our study. Class 3 findings were suspicious for malignancies, metastatic disease or vascular aneurysms, which might represent a life-threatening condition to the patient's health. Also, steps should be taken to increase the patient's knowledge regarding a normal anatomical variant or benign finding, like those in class 1 , which may prevent future confusion or unnecessary investigations.

On the other hand, incidental findings increase the challenge and work load of physicians. During trauma management, there are many incidental findings that are not important during the initial trauma care, but still might be important for patient's further health. Therefore, the clinical relevance of these findings needs to be weighed against the patient's actual injuries and also against the patient's future health. Early identification of incidental findings increases patient survival and decreases morbidity. ${ }^{12}$ However, overdiagnosis might lead to unnecessary diagnostic testing. ${ }^{13}$ Shetty et al looked at thyroid nodules found incidentally on CT scan. ${ }^{17}$ Of 230 patients who were found to have thyroid nodule, 118 underwent biopsy and 22\% were found to be malignant. It has also been reported that $29 \%$ of incidentally discovered adrenal masses $>3 \mathrm{~cm}$ in diameter were determined to be malignant. ${ }^{9}{ }^{18}$ Even asymptomatic biliary or renal stones found on CT scan are helpful to patient's physician or other healthcare providers in the future if these stones become symptomatic. ${ }^{14}$ In our study, we found 18 patients in the incidental group that were identified with otherwise normal anomalies listed as incidental by the radiologist based on dimensional review of the CT scan.

Another challenge in the management of these findings is patients who are discharged from the ED after completion of trauma evaluation but before the completion of official CT scan reports. Patients may be sent home based on preliminary negative CT scan for trauma injuries that later are amended with a report of incidental findings. ${ }^{14} 21$ Furthermore, a continued follow-up is the key in evaluating patient progress, trauma service equipped with a liaison service to review patient outcomes in quality control could advise and follow-up on these findings.

Finally, the hospital length of stay was noted to be longer for patients with incidental findings compared with those without (8.7 vs 6.4 days). This finding was further broken down into the classification system we created to look at the class distribution of the length of stay. Patients with class 3 findings had the longest length of stay, followed by class 2 and class 1 without significance. In class 2 and class 3 , the mean length of stay was 9 days $(9.0 \pm 11.3$ and $9.8 \pm 17.0$, respectively) and 7 days for class 1 (7.2 \pm 6.9 days). This could be explained by the need for more imaging studies and consultations to be done for patients with incidental findings that were identified. If patients in class 2 and class 3 were evaluated with our proposed classification, this length of stay of 9 days could have been stratified and reduced with an outpatient referral follow-up system in place. This also may have impact on increasing the healthcare cost, especially if the patient has a benign lesion that does not require any intervention.

\section{Limitations}

There are several limitations to our analysis. First, our study is retrospective and subject to multiple biases from differences in our patient populations to different risk factors than other regions. Thus, the results may not be applicable to all hospitals. A prospective study could be proposed with our system to further evaluate quality metrics. Second, there was little documentation about any further follow-up or intervention done postdischarge. It is possible that the patients were verbally given follow-up instructions; if this is the case, lapses in documentation are still of concern. Finally, this study is a shortterm study. There was no long-term follow-up. Therefore, the data regarding how many biopsies were performed may not be beneficial.

\section{CONCLUSION}

Incidental findings are commonly found during CT imaging in trauma centers. The rate of incidental findings (40\%) in our center is in line with the national range, which is between $30 \%$ and 53\%. Appropriate documentation, communication and follow-up of these incidental findings is necessary. A classification system for these findings practiced nationwide will aid in categorizing the urgency of further follow-up, once a trauma emergency has been stratified. This will help decrease hospital length of stay and overall healthcare cost.

Acknowledgements The authors would like to acknowledge the trauma nursing team in the Division of Trauma for granting access to Trauma Database and data validation: Christopher Sorrentino (Pediatric Trauma Program Manager), Holly Acierno (Performance Improvement Coordinator) and Eric Cohen (Trauma Program Manager). In addition, the authors thank Meagan Sills in the Department of Research for collating the studies and monitoring the progress. Doctors Ariful Alam, Christopher Daniele and Aldo Gamarra with assistance in data collection. 
Contributors PA: study design, development of methodology, data analysis, data collection, writing sections of the manuscript. AAP: study design, development of methodology, supervision. MAS: data analysis, data collection, writing sections of the manuscript. BA: study design, development of methodology, data analysis. WVW: data collection, data analysis. SD: statistical analysis. CF: study design, data analysis, supervision.

Competing interests None declared.

Ethics approval IRB\# SIUH11-074.

Provenance and peer review Not commissioned; externally peer reviewed.

Open Access This is an Open Access article distributed in accordance with the Creative Commons Attribution Non Commercial (CC BY-NC 4.0) license, which permits others to distribute, remix, adapt, build upon this work non-commercially, and license their derivative works on different terms, provided the original work is properly cited and the use is non-commercial. See: http://creativecommons.org/ licenses/by-nc/4.0/

(c) Article author(s) (or their employer(s) unless otherwise stated in the text of the article) 2017. All rights reserved. No commercial use is permitted unless otherwise expressly granted.

\section{REFERENCES}

1 Motor vehicle accidents—number and deaths: 1990 to 2009, United States census Bureau. U.S. Department of Commerce https://www2.census.gov/library/publications/ 2011/compendia/statab/131ed/tables/trans.pdf (accessed 12 May 2016).

2 DeGrauw X, Annest JL, Stevens JA, Xu L, Coronado V. Unintentional injuries treated in hospital emergency departments among persons aged 65 years and older, United States, 2006-2011. J Safety Res 2016;56:105-9.

3 Salim A, Sangthong B, Martin M, Brown C, Plurad D, Demetriades D. Whole body imaging in blunt multisystem trauma patients without obvious signs of injury: results of a prospective study. Arch Surg 2006;141:468-73.

4 Sampson MA, Colquhoun KB, Hennessy NL. Computed tomography whole body imaging in multi-trauma: 7 years experience. Clin Radiol 2006;61:365-9.

5 Wisbach GG, Sise MJ, Sack DI, Swanson SM, Sundquist SM, Paci GM, Kingdon KM, Kaminski SS. What is the role of chest $\mathrm{X}$-ray in the initial assessment of stable trauma patients? J Trauma 2007:62:74-9.

6 You JS, Lee HJ, Chung YE, Lee HS, Kim MJ, Chung SP, Kim MJ, Park I, Kim KW. Diagnostic radiation exposure of injury patients in the emergency department: a cross-sectional large scaled study. PLoS One 2013;8:e84870.
7 Paluska TR, Sise MJ, Sack DI, Sise CB, Egan MC, Biondi M. Incidental CT findings in trauma patients: incidence and implications for care of the injured. J Trauma 2007;62:157-61.

8 Seah MK, Murphy CG, McDonald S, Carrothers A. Incidental findings on wholebody trauma computed tomography: Experience at a major trauma centre. Injury 2016;47:691-4.

9 Munk MD, Peitzman AB, Hostler DP, Wolfson AB. Frequency and follow-up of incidental findings on trauma computed tomography scans: experience at a level one trauma center. J Emerg Med 2010;38:346-50.

10 Ekeh AP, Walusimbi M, Brigham E, Woods RJ, McCarthy MC. The prevalence of incidental findings on abdominal computed tomography scans of trauma patients. J Emerg Med 2010;38:484-9.

11 Devine AS, Jackson CS, Lyons L, Mason JD. Frequency of incidental findings on computed tomography of trauma patients. West J Emerg Med 2010;11:24-7.

12 Ruesseler M, Schill A, Lehnert T, Wyen H, Wutzler S, Marzi I, Walcher F. Incidental findings in patients with multiple injuries: how to proceed? I Trauma Acute Care Surg 2013;75:848-53

13 Sierink JC, Saltzherr TP, Russchen MJ, de Castro SM, Beenen LF, Schep NW, Goslings JC. Incidental findings on total-body CT scans in trauma patients. Injury 2014;45:840-4.

14 Barrett TW, Schierling M, Zhou C, Colfax JD, Russ S, Conatser P, Lancaster P, Wrenn $K$. Prevalence of incidental findings in trauma patients detected by computed tomography imaging. Am J Emerg Med 2009;27:428-35.

15 ACS NTDB (National Trauma Data Standard). Data Dictionary Committee On Trauma, 2014 Admissions. American College of Surgeons. Released August, 2014.

16 Berland LL, Silverman SG, Gore RM, Mayo-Smith WW, Megibow AJ, Yee J, Brink JA, Baker $M E$, Federle MP, Foley WD, et al. Managing incidental findings on abdominal CT: white paper of the ACR incidental findings committee. J Am Coll Radiol 2010;7:754-73.

17 Shetty SK, Maher MM, Hahn PF, Halpern EF, Aquino SL. Significance of incidental thyroid lesions detected on CT: correlation among $\mathrm{CT}$, sonography, and pathology. AJR Am J Roentgenol 2006;187:1349-56.

18 Lumachi F, Borsato S, Tregnaghi A, Marino F, Fassina A, Zucchetta P, Marzola MC, Cecchin D, Bui F, lacobone M, et al. High risk of malignancy in patients with incidentally discovered adrenal masses: accuracy of adrenal imaging and imageguided fine-needle aspiration cytology. Tumori 2007;93:269-74.

19 Barboza R, Fox JH, Shaffer LE, Opalek JM, Farooki S. Incidental findings in the cervical spine at CT for trauma evaluation. AJR Am J Roentgenol 2009;192:725-9.

20 Maizlin ZV, Barnard SA, Gourlay WA, Brown JA. Economic and ethical impact of extrarenal findings on potential living kidney donor assessment with computed tomography angiography. Transp/ Int 2007;20:338-42.

21 Thompson RJ, Wojcik SM, Grant WD, Ko PY. Incidental Findings on CT Scans in the Emergency Department. Emerg Med Int 2011;2011:1-4. 